\title{
PENINGKATAN KETERAMPILAN MENULIS PANTUN MELALUI MEDIA GAMBAR PADA SISWA KELAS VIII SMP HKBP SIDIKALANG
}

\author{
Yowana Putri ${ }^{1}$, Ramadhan Saleh Lubis ${ }^{2}$, Resi Masna Warni Saragih ${ }^{3}$, Anggreini Sitorus ${ }^{4}$, \\ Farida Br Simarmata ${ }^{5}$ \\ Universitas Prima Indonesia ${ }^{1}$, Universitas Prima Indonesia ${ }^{2}$, Universitas Prima Indonesia ${ }^{3}$, \\ Universitas Prima Indonesia ${ }^{4}$, Universitas Prima Indonesia ${ }^{5}$ \\ pos-el: yonaputri58@gmail.com¹, ramadhansaleh986@yahoo.com² ${ }^{2}$ Saragihresi3@gmail.com³, \\ anggreinisitorus4@gmail.com ${ }^{4}$, faridarointan33@gmail.com ${ }^{5}$
}

\begin{abstract}
ABSTRAK
Penelitian ini bertujuan untuk meningkatkan keterampilan menulis pantun melalui media gambar. Data yang peneliti ambil bersumber dari kelas VIII 1 SMP Swasta HKBP dengan jumlah 30 siswa. Jika dilihat dari hasil tes, masih ada siswa yang belu memahami langkahlangkah dan kaidah menulis pantun. Siswa masih kesulitan menuangkan ide-ide serta kosa kata yang mereka miliki. Penelitian ini adalah jenis PTK dengan menggunakan media gambar dan teknik pengumpulan data dengan observasi dan tes. Hasil penelitian menunjukkan bahwa proses peningkatan keterampilan menulis pantun melalui media gambar mengalami peningkatan. Hal ini dapat dilihat dari hasil rata-rata setiap siklus, pada tahap prasiklus hanya mencapai rata-rata 69,1 dan belum mencapai indikator. Namun, terjadi peningkatan pada siklus I dengan rata-rata 79,5 dan pada siklus II terjadi peningkatan kembali dengan rata-rata 82,7. Dengan ini peneliti menyatakan bahwa pembelajaran menulis pantun melalui media gambar dapat meningkatkan keterampilan siswa dalam menulis pantun.
\end{abstract}

Kata kunci: Meningkatkan keterampilan menulis pantun, Kelas VIII, Media gambar.

\begin{abstract}
This study aims to improve rhyme writing skills through image media. The data that the researchers used was sourced from class VIII 1 of HKBP Private Junior High School, with a total of 30 students. When viewed from the test results, there are still students who do not understand the steps and rules of rhyme writing. Students still have difficulty expressing their ideas and vocabulary. This research is a type of CAR by using image media and data collection techniques with observations and tests. The results showed that the process of improving rhyme writing skills through image media has increased. This can be seen from the average results of each cycle. At the pre-cycle stage, it had only reached an average of 69.1 and had not yet reached the indikator. However, there was an increase in the first cycle with an average of 79.5, and in the second cycle there was an increase again with an average of 82.7. Hereby, the researcher states that learning to write rhymes through image media can improve students' skills in writing rhymes.
\end{abstract}

Keywords: Improving poetry writing skills, Class VIII, Picture Media.

\section{PENDAHULUAN}

Menurut Nurgiantoro (2008: 294), menulis merupakan suatu bentuk manifestasi kemampuan berbahasa yang paling akhir dikuasai oleh siswa setelah kemampuan mendengarkan, berbicara, dan membaca. Dari keempat hal tersebut, menulis lebih sulit untuk dikuasai. kemampuan menulis perlu penguasaan unsur kebahasaan dan unsur di luar bahasa itu sendiri sehingga dapat menjadi tulisan. Menulis biasanya dilakukan pada media kertas dengan menggunakan 
alat- alat seperti pena dan pensil. Dengan adanya media pembelajaran itu akan sangat membantu guru dalam menyampaikan pesan-pesan atau materi pelajaran kepada siswanya, agar pesan lebih mudah dipahami siswa, lebih menarik perhatian siswa, dan lebih menyenangkan siswa dalam kegiatan belajar mengajar.

Menulis pantun sama halnya dengan menulis puisi, memerlukan konsentrasi dan imajinasi yang khusus. Menulis pantun mengharuskan kita untuk teliti dalam langkah-langkah serta kaidah menuliskan pantun. Alisyabana (2004:1) berpendapat bahwa pantun adalah satu di antara jenis puisi lama yang dikenal oleh orang dulu dan telah dikenal masyarakat sejak lama sekali. Ciri utama pada pantun adalah setiap baitnya terdiri dari empat baris yang mana empat baris itu terdiri dari baris pertama dan kedua yang disebut sampiran serta baris ketiga dan keempat disebut isi pantun.

Keterampilan menulis pantun pada siswa kelas VIII 1 SMP Swasta HKBP Sidikalang masih dikatakan rendah, hal ini dikarenakan hasil tes menulis pantun siswa yang masih salah dalam menyamakan rima, serta masih ada siswa yang hasil tesnya sama dengan teman yang lainnya. Maka, pemecahan untuk masalah ini adalah dengan melalui media gambar untuk meningkatkan kemampuan siswa dalam menulis pantun. Karena dengan adanya gambar siswa akan lebih mudah menulis pantun dan dapat mengimajinasikan kata-kata siswa berdasarkan gambar yang ada pada kertas siswa. Berdasarkan latar belakang ini, penggunaan media gambar sebagai sarana menulis pantun perlu peneliti teliti untuk meningkatkan keterampilan menulis pantun pada siswa kelas VIII 1 SMP Swasta HKBP Sidikalang.

\section{METODE PENELITIAN}

Penelitian ini menggunakan penelitian tindakan kelas (PTK). Hopkins (2009:8) menerangkan Penelitian Tindakan Kelas (PTK) adalah suatu bentuk kajian yang bersifat refleksi, yang dilakukan oleh pelaku tindakan untuk meningkatkan kemantapan rasional dari tindakantindakannya dalam melaksanakan tugas dan memperdalam pemahaman terhadap kondisi dalam praktis pembelajaran. Arikunto (2009:3) juga mendefinisikan "PTK sebagai suatu kegiatan belajar berupa sebuah tindakan yang sengaja dimunculkan dan terjadi dalam sebuah kelas secara bersama.

Penelitian ini dilaksanakan untuk mengetahui ada atau tidak peningkatan menulis pantun siswa kelas VIII 1 SMP Swasta HKBP Sidikalang dengan melalui media gambar. Metode yang digunakan peneliti dalam penelitian ini adalah deskriptif. Metode ini digunakan untuk mengetahui apa-apa yang ada

di lapangan atau kenyataan hasil penelitian. Hal ini dijelaskan oleh Sugiyono (2005: 21) menyatakan bahwa metode deskriptif adalah suatu metode yang digunakan untuk menggambarkan atau menganalisis suatu hasil penelitian tetapi tidak digunakan untuk membuat kesimpulan yang lebih luas.

Penelitian ini dilakukan pada tanggal 15 Juli-03 Desember 2021 secara bertahap di kelas VIII 1 SMP Swasta HKBP Sidikalang yang beralamat di jalan Gereja No. 1 Sidikalang, Kabupaten Dairi. Penelitian ini bersumber dari Siswa-siswa kelas VIII 1 SMP Swasta HKBP Sidikalang. Teknik pengumpulan data pada penelitian ini adalah dengan teknik melalui observasi dan teknik tes. Observasi ialah teknik pengumpulan data dengan cara mengamati secara langsung atau tidak langsung. Penelitian ini dilakukan dengan terjun langsung agar mendapatkan data yang akurat. 
Setelah observasi peneliti melakukan tes. Arikunto (2007:53) berpendapat bahwa tes adalah alat atau prosedur yang digunakan untuk mengetahui atau mengukur sesuatu dengan cara-cara atau aturan-aturan yang telah ditentukan. Untuk melihat bagaimana kemampuan siswa kelas VIII
1 dalam menciptakan pantun dengan menggunakan media gambar. Tes ini dilakukan tiga kali. Untuk menilai kemampuan menulis pantun siswa, peneliti menilai dengan mengamati tulisan siswa dalam langkah-langkah menulis pantun sesuai kaidahnya.

Tabel 1. Keterangan penilaian

\begin{tabular}{|l|l|}
\hline Keterangan Nilai & Penilaian \\
\hline Baik (Peningkatan sangat baik 80>) & $\begin{array}{l}\text { Ketepatan sajak atau rima, keseuaian } \\
\text { gambar/tema, penggunakan kosa kata. }\end{array}$ \\
\cline { 1 - 2 } Cukup (Mulai ada peninglatan 70-79) & \\
\hline
\end{tabular}

\section{HASIL DAN PEMBAHASAN}

Pelaksanaan penelitian siswa kelas VIII 1 SMP Swasta HKBP Sidikalang berupa tes dilaksanakan tiga kali. yaitu prasiklus, siklus pertama dan siklus kedua, yang mana di dalam kelas setiap individu harus menulis pantun di kertas yang sudah peneliti sediakan, setiap tahap dilakukan selama 90 menit.

Tabel 2. Tahap Penelitian

\begin{tabular}{|l|l|l|}
\hline Prasiklus & Siklus 1 & Siklus 2 \\
\hline & $\begin{array}{l}\text { Penjelasan } \\
\text { /penelitian }\end{array}$ & $\begin{array}{l}\text { Penjelasan/ } \\
\text { penelitian }\end{array}$ \\
\hline Tes & Tes & Tes \\
\hline Penilaian & Penilaian & Penilaian \\
\hline
\end{tabular}

\section{Tahap Prasiklus}

Hasil penelitian yang didapat di kelas VIII 1 SMP Swasta HKBP Sidikalang, dalam meningkatkan keterampilan menulis pantun melalui media gambar pada tahap prasiklus langkah pertama yang dilalukan adalah peneliti memberi tahu kepada siswa mengenai maksud dan tujuan peneliti datang ke sekolah mereka dan peneliti meminta siswa untuk menulis pantun berdasarkan tema yang tertera pada kertas yang akan diberikan oleh peneliti kepada siswa, kertas tersebut hanya berisikan tema dan tanpa memberikan penjelasan tentang pantun dan tanpa memberikan gambar pada kertas tersebut.

Setelah dilaksanakan tes tersebut ternyata masih banyak siswa yang belum memahami langkah-langkah menulis pantun serta kaidah menulis pantun. Ada beberapa siswa yang tidak bisa menulis pantun dengan rima yang sama, menulis pantun yang sama dengan temannya, ada pula siswa yang menuliskan pantun tanpa mengikuti tema yang tertera pada kertas yang diberikan oleh peneliti, dan masih ada siswa yang kurang fokus dalam mengerjakan tes ini. Hanya beberapa siswa yang mampu mengerjakan tes ini walaupun kosa kata yang diambil masih kurang tepat. Nilai rata-rata dari hasil tes pada tahap prasiklus dapat dilihat pada tabel berikut. 
Tabel 3. Nilai Tes pada Tahap Prasiklus

\begin{tabular}{|c|c|c|}
\hline NO & NAMA & $\begin{array}{l}\text { PRASI } \\
\text { KLUS }\end{array}$ \\
\hline 1 & AndreF.Ginting & 60 \\
\hline 2 & Andreas Naibaho & 65 \\
\hline 3 & Antonius & 67 \\
\hline 4 & Cavin Sitanggang & 66 \\
\hline 5 & Ciren Nuraini Sinaga & 72 \\
\hline 6 & Clesya Siregar & 65 \\
\hline 7 & Desman Sinambela & 66 \\
\hline 8 & Destinari manullang & 71 \\
\hline 9 & Elisa Situmorang & 72 \\
\hline 10 & Erwin Tumangger & 67 \\
\hline 11 & Ferdayati Banurea & 75 \\
\hline 12 & Gres Enjel Naulibako & 80 \\
\hline 13 & Hendri Banjarnahor & 65 \\
\hline 14 & Irwan Sitinjak & 60 \\
\hline 15 & Januari Simbolon & 60 \\
\hline 16 & $\begin{array}{l}\text { Kristiani } \\
\text { Lumbangaol }\end{array}$ & 63 \\
\hline 17 & Mariahot tina & 72 \\
\hline 18 & Budiman Sianturi & 72 \\
\hline 19 & Paramita Sihombing & 68 \\
\hline 20 & Pakah Sinaga & 66 \\
\hline 21 & Piana Ayu lestari & 68 \\
\hline 22 & Rindu lumbangaol & 80 \\
\hline 23 & Sebastian & 76 \\
\hline 24 & Shandi Siregar & 74 \\
\hline 25 & Gabriel sianturi & 72 \\
\hline 26 & TasyaMetalia Siregar & 75 \\
\hline 27 & Vebiloren Saberutu & 73 \\
\hline 28 & Vetra Sihotang & 65 \\
\hline 29 & Witria Sinaga & 60 \\
\hline 30 & Zein Marbun & 78 \\
\hline Jumlah & Rata-rata & 69,1 \\
\hline
\end{tabular}

\section{Tahap Siklus I}

Pada siklus ini peneliti melakukan tindakan presentasi dengan menjelaskan apa itu pantun, langkah-langkah menulis pantun, serta cara menulis pantun yang benar. Peneliti sebelumnya sudah menjelaskan apa maksud peneliti datang kembali dan memberikan mereka tes dengan judul besar yang sama seperti pada tahap prasiklus sbelumnya. Kemudian tahapan selanjutnya yaitu peneliti memberikan kertas yang berisikan suatu gambar kepada masing-masing siswa, dan peneliti memerintahkan siswa untuk menulis pantun berdasarkan gambar pada kertas yang masing-masing siswa dapatkan.

Peneliti meneliti setiap siswa yang sedang menulis, dapat peneliti lihat bahwa banyak siswa yang lebih mengerti mengerjakan tes ini dengan adanya gambar pada tes, ide-ide yang mereka miliki juga dapat tersalurkan karena adanya gambar yang dapat membantu mereka dalam mengerjakan tes tersebut. Tetapi masih ada sebagian siswa yang masih kesulitan dalam menulis tes ini, setelah diteliti ternyata siswa tersebut sulit dalam memusatkan atau sulit untuk berkonsentrasi, bahkan ada siswa yang masih lambat dalam menulis, siswa tersebut kurang mampu menyatukan kata per kata agar menjadi satu kalimat yang utuh.

Sulitnya siswa untuk memusatkan perhatian atau fokus pada tes di kelas VIII 1 ini berkemungkinan karena suara siswa yang sulit terkontrol, banyak siswa yang kurang disiplin, ngobrol dengan teman yang lain, itulah yang dapat membuat siswa sulit berkonsentrasi. Peneliti memberikan arahan agar suasana kelas dapat terkontrol dengan baik.

Tabel 4. Nilai Tes pada Siklus I

\begin{tabular}{|l|l|l|}
\hline NO & NAMA & $\begin{array}{l}\text { SIKLUS } \\
1\end{array}$ \\
\hline 1 & AndreF.Ginting & 78 \\
\hline 2 & Andreas Naibaho & 80 \\
\hline 3 & $\begin{array}{l}\text { Antonius lumban } \\
\text { batu }\end{array}$ & 80 \\
\hline 4 & $\begin{array}{l}\text { Cavin Julio } \\
\text { Sitanggang }\end{array}$ & 85 \\
\hline 5 & Ciren Nuraini Sinaga & 85 \\
\hline 6 & Clesya Siregar & 78 \\
\hline 7 & $\begin{array}{l}\text { Desman Natanael } \\
\text { Sinambela }\end{array}$ & 75 \\
\hline
\end{tabular}




\begin{tabular}{|c|c|c|}
\hline 8 & $\begin{array}{ll}\begin{array}{l}\text { Destinari } \\
\text { manullang }\end{array} & \text { nawati } \\
\end{array}$ & 85 \\
\hline 9 & Elisa Situmorang & 85 \\
\hline 10 & $\begin{array}{l}\text { Erwin Sahputra } \\
\text { Tumangger }\end{array}$ & 80 \\
\hline 11 & Ferdayati Banurea & 80 \\
\hline 12 & Gres Enjel Naulibako & 80 \\
\hline 13 & Hendri Banjarnahor & 70 \\
\hline 14 & $\begin{array}{ll}\text { Irwan } & \text { Samuel } \\
\text { Sitinjak } & \\
\end{array}$ & 68 \\
\hline 15 & $\begin{array}{ll}\text { Januari } & \text { deCaprio } \\
\text { Simbolon } & \\
\end{array}$ & 77 \\
\hline 16 & $\begin{array}{l}\text { Kristiani } \\
\text { Lumbangaol }\end{array}$ & 80 \\
\hline 17 & Mariahot tina & 85 \\
\hline 18 & Budiman Sianturi & 85 \\
\hline 19 & Paramita Sihombing & 78 \\
\hline 20 & $\begin{array}{l}\text { Pakah palensiah } \\
\text { Sinaga }\end{array}$ & 78 \\
\hline 21 & Piana Ayu lestari & 80 \\
\hline 22 & Rindu lumbangaol & 85 \\
\hline 23 & $\begin{array}{l}\text { Sebastian } \\
\text { Rajagukguk }\end{array}$ & 80 \\
\hline 24 & Shandi Siregar & 80 \\
\hline 25 & $\begin{array}{l}\text { Gabriel } \\
\text { Suriadisianturi }\end{array}$ & 80 \\
\hline 26 & TasyaMetalia Siregar & 78 \\
\hline 27 & Vebiloren Saberutu & 80 \\
\hline 28 & $\begin{array}{ll}\text { Vetra } & \text { Novella } \\
\text { Sihotang } & \end{array}$ & 77 \\
\hline 29 & Witria Sinaga & 68 \\
\hline 30 & Zein Marbun & 85 \\
\hline Jumlah & Rata-rata & 79,5 \\
\hline
\end{tabular}

\section{Tahap Siklus II}

Pada siklus ini peneliti menjelaskan kembali mengenai pantun, sebelum menjelaskan peneliti memberi sedikit arahan dan motivasi kepada siswa kelas VIII 1 agar lebih semangat belajar, dan selalu menjaga kebersihan kemudian peneliti membagikan kertas yang berisikan gambar dilengkapi dengan tema pada tiap-tiap siswa, setelah itu peneliti mengarahkan siswa untuk semakin bersemangat menulis pantun dikarenakan peneliti mencantumkan tema dan gambar pada kertas yang membuat siswa semakin mudah menulis pantun

Tabel 5. Nilai Tes Siklus II

\begin{tabular}{|c|c|c|}
\hline $\mathrm{NO}$ & NAMA & $\begin{array}{l}\text { SIKLUS } \\
\text { II }\end{array}$ \\
\hline 1 & AndreF.Ginting & 85 \\
\hline 2 & Andreas Naibaho & 85 \\
\hline 3 & Antonius lumban batu & 88 \\
\hline 4 & $\begin{array}{ll}\text { Cavin } & \text { Julio } \\
\text { Sitanggang } & \end{array}$ & 85 \\
\hline 5 & Ciren Nuraini Sinaga & 85 \\
\hline 6 & Clesya Siregar & 80 \\
\hline 7 & Desman Sinambela & 80 \\
\hline 8 & Destinari & 90 \\
\hline 9 & Elisa Situmorang & 88 \\
\hline 10 & Erwin Sahputra & 80 \\
\hline 11 & Ferdayati Banurea & 85 \\
\hline 12 & Gres Enjel Naulibako & 90 \\
\hline 13 & Hendri Banjarnahor & 80 \\
\hline 14 & Irwan Samuel Sitinjak & 78 \\
\hline 15 & Januari deCaprio & 78 \\
\hline 16 & Kristiani Lumbangaol & 80 \\
\hline 17 & Mariahot tina & 90 \\
\hline 18 & Budiman Sianturi & 85 \\
\hline 19 & Paramita Sihombing & 84 \\
\hline 20 & $\begin{array}{ll}\text { Pakah } & \text { palensiah } \\
\text { Sinaga } & \\
\end{array}$ & 78 \\
\hline 21 & Piana Ayu lestari & 90 \\
\hline 22 & Rindu lumbangaol & 86 \\
\hline 23 & Sebastian Rajagukguk & 79 \\
\hline 24 & Shandi Siregar & 80 \\
\hline 25 & Gabriel Suriadisianturi & 80 \\
\hline 26 & TasyaMetalia Siregar & 80 \\
\hline 27 & Vebiloren Saberutu & 78 \\
\hline 28 & $\begin{array}{ll}\text { Vetra } & \text { Novella } \\
\text { Sihotang } & \\
\end{array}$ & 80 \\
\hline 29 & Witria Sinaga & 68 \\
\hline 30 & Zein Marbun & 87 \\
\hline Jumlah & Rata-rata & 82,7 \\
\hline
\end{tabular}

menuliskan pantun berdasarkan tema dan gambar yang ada pada kertas mereka. Peneliti melihat bahwa siswa 
Hasil dari setiap tahap yang dilakukan siswa dalam menulis pantun terdapat peningkatan, keterampilan menulis pantun pada siswa dapat siswa masih memperoleh nilai rendah dikarenakan tes hanya berisi tema, pada siklus I terjadi peningkatan nilai dikarenakan penggunaan media gambar untuk menulis pantun pada siswa kelas VIII 1 sudah peneliti gunakan, dan pada siklus II juga mengalami peningkatan sebab, peneliti menggunakan media gambar beserta tema.

\section{KESIMPULAN}

Berdasarkan hasil penelitian terhadap peningkatan keterampilan menulis pantun melalui media gambar pada siswa kelas VIII 1 SMP Swasta HKBP SIDIKALANG dapat disimpulkan bahwa, penggunaan media gambar dapat meningkatkan keterampilan menulis pantun pada siswa, hal ini dapat dilihat dari hasil tes siswa yang sangat bervariasi dalam memilih kata yang sesuai dengan gambar yang peneliti berikan, bahkan siswa mampu menuliskan pantun berdasarkan gambar dan tema tersebut sesuai dengan syarat-syarat dan kaidah menulis pantun.

\section{DAFTAR PUSTAKA}

Alisyahbana, Sutan Takdir. 1979. Puisi lama. Jakarta: Dian Rakyat

Arikunto, Suharsimi, dkk.2006. Penelitian tindakan kelas. Jakarta: Bumi Aksara

Arikunto, Suharsimi. 2007. Manajemen Penelitian. Jakarta: Rineka Cipta

Arikunto, Suharsimi. 2009. DasarDasar Evaluasi Pendidikan. Jakarta: Bumi Aksara

Nurgiantoro, Burha. 2008. Dasar-Dasar Pengembangan Kurikulum. BPFE, Yogyakarta ditingkatkan melalui media gambar dengan memberikan sedikit arahan dan penjelasan mengenai pantun. Hal ini terbukti pada tahap prasiklus yang mana Tabel 6. Peningkatan Siswa dalam Menulis Pantun dengan Melalui Media Gambar pada Tahap Prasiklus, Siklus I dan Siklus II

\begin{tabular}{|l|l|l|l|l|}
\hline $\begin{array}{l}\text { N } \\
\text { o }\end{array}$ & Nilai & prasiklus & Siklus 1 & Siklus 2 \\
\hline 1 & Baik & 2Siswa & 19 siswa & 24 siswa \\
2 & Cukup & 12 siswa & 9 Siswa & 5 Siswa \\
3 & Kurang & 16 siswa & 2 Siswa & 1 Siswa \\
\hline
\end{tabular}

Penggunaan media gambar juga dapat meningkatkan ide-ide dan kosa kata yang digunakan siswa dalam menulis pantun, terjadi peningkatan nilai dari tahap prasiklus dengan ratarata 69,1 kemudian pada tahap siklus I nilai rata-rata meningkat menjadi 79,5 pada tahap siklus II nilai rata-rata meningkat lagi menjadi 82,7. Dari hasil nilai yang siswa peroleh maka, penelitian ini dikatakan berhasil dan dugaan sementara diterima bahwa dengan menggunakan media gambar dapat meningkatkan keterampilan dalam menulis pantun bagi siswa kelas VIII 1 SMP Swasta HKBP SIDIKALANG.

Rahmanto, B. 2004. Metode Pengajaran Sastra. Yogyakarta: Kanisius

Sugiyono.2005. Memahami Penelitian Kualitatif. Bandung: CV. Alfabeta Sugiyono (2015). Metode Penelitian Kombinasi (Mix Methods). Bandung: Alfabeta

Suprapto,V. "Penggunaan Contextual Teaching and Learning (CTL) Berbantuan Kartu Kata Untuk Meningkatkan Keterampilan Menulis Pantun Pada Siswa $S D$ '.Linguista: 
Jurnal Ilmiah Bahasa,Sastra,dan Pembelajarannya,2020

Resnani Resnani." Meningkatkan Kemampuan Menulis Pantun Siswa Melalui Model Multiliterasi", Jurnal PGSD: Jurnal Ilmiah Pendidikan Guru Sekolah Dasar,2021.
Indra

Prada

Kusuma.

2012. "Peningkatan Keterampilan Menulis Pantun Melalui Model Pembelajaran Think Pair Share Berbantuan Media Powerpoint Kelas IV SD Negeri Karanganyar”. Skripsi. UIN Jakarta. 